\title{
Sodium restriction in patients with chronic heart failure and reduced ejection fraction: A randomized controlled trial
}

Juan B. Ivey-Miranda ${ }^{1}$, Eduardo Almeida-Gutierrez ${ }^{2}$, Raul Herrera-Saucedo ${ }^{1}$, Edith L. Posada-Martinez ${ }^{3}$, Adolfo Chavez-Mendoza ${ }^{1}$, Genaro H. Mendoza-Zavala ${ }^{1}$, Jose A. Cigarroa-Lopez ${ }^{1}$, Jose A. Magaña-Serrano ${ }^{1}$, Roxana Rivera-Leaños ${ }^{4}$, Alberto Treviño-Mejia ${ }^{4}$, Cristina Revilla-Monsalve ${ }^{5}$, Eduardo J. Flores-Umanzor ${ }^{6}$, Nilda Espinola-Zavaleta ${ }^{7}$, Arturo Orea-Tejeda ${ }^{8}$, Juan Garduño-Espinosa ${ }^{9}$, Guillermo Saturno-Chiu', Veena S. Rao ${ }^{10}$, Jeffrey M. Testani ${ }^{10}$, Gabriela Borrayo-Sanchez ${ }^{11}$

${ }^{1}$ Department of Heart Failure, Hospital de Cardiologia, Centro Medico Nacional Siglo XXI, Instituto Mexicano del Seguro Social, Mexico City, Mexico

${ }^{2}$ Department of Research and Direction, Hospital de Cardiologia, Centro Medico Nacional Siglo XXI, Instituto Mexicano del Seguro Social, Mexico City, Mexico

${ }^{3}$ Department of Echocardiography, Instituto Nacional de Cardiologia Ignacio Chavez, Mexico City, Mexico

${ }^{4}$ Department of Laboratory, Hospital de Cardiologia, Centro Medico Nacional Siglo XXI,

Instituto Mexicano del Seguro Social, Mexico City, Mexico

${ }^{5}$ Unidad de Investigación Médica en Enfermedades Metabólicas, Hospital de Cardiologia,

Centro Medico Nacional Siglo XXI, Instituto Mexicano del Seguro Social, Mexico City

${ }^{6}$ Department of Cardiology. Hospital Clinic de Barcelona, Barcelona, Spain

${ }^{7}$ Department of Nuclear Medicine, Instituto Nacional de Cardiologia Ignacio Chavez, Mexico City, Mexico

${ }^{8} \mathrm{Head}$ of Cardiology Department, Instituto Nacional de Enfermedades Respiratorias Ismael Cosío Villegas, Mexico City, Mexico

${ }^{9}$ Directorate of Research, Hospital Infantil de México Federico Gómez, Mexico City, Mexico

${ }^{10}$ Department of Internal Medicine, Section of Cardiovascular Medicine,

Yale University School of Medicine, New Haven, Connecticut, United States

${ }^{11}$ Program "A Todo Corazon", Centro Medico Nacional Siglo XXI,

Instituto Mexicano del Seguro Social, Mexico City, Mexico

\begin{abstract}
Background: Sodium restriction is recommended for patients with heart failure (HF) despite the lack of solid clinical evidence from randomized controlled trials. Whether or not sodium restrictions provide beneficial cardiac effects is not known.

Methods: The present study is a randomized, double-blind, controlled trial of stable HF patients with ejection fraction $\leq 40 \%$. Patients were allocated to sodium restriction (2 $g$ of sodium/day) vs. control (3 $\mathrm{g}$ of sodium/day). The primary outcome was change in $N$-terminal pro-B-type natriuretic peptide (NT-proBNP) at 20 weeks. Secondary outcomes included quality of life and adverse safety events (HF readmission, blood pressure or electrolyte abnormalities).
\end{abstract}

Address for correspondence: Dr. Gabriela Borrayo-Sanchez, MD, PhD, Program “A Todo Corazón”, Centro Medico Nacional Siglo XXI, Instituto Mexicano del Seguro Social, 330 Cuauhtemoc Avenue, Mexico City, Mexico, ZC 06720, tel: (+52) 554368 3768, e-mail: gabriela.borrayo@imss.gob.mx

Received: 23.04.2021 Accepted: 11.08.2021 Early publication date: 26.08.2021

This article is available in open access under Creative Common Attribution-Non-Commercial-No Derivatives 4.0 International (CC BY-NC-ND 4.0) license, allowing to download articles and share them with others as long as they credit the authors and the publisher, but without permission to change them in any way or use them commercially. 
Results: Seventy patients were enrolled. Median baseline sodium consumption was 3268 (2225-4537) $m g / d a y$. Adherence to the intervention based on 24-hour urinary sodium was $32 \%$. NT-proBNP and quality of life did not significantly change between groups ( $p>0.05$ for both). Adverse safety events were not significantly different between the arms $(p>0.6$ for all). In the per protocol analysis, patients who achieved a sodium intake $<2500 \mathrm{mg} /$ day at the intervention conclusion showed improvements in NT-proBNP levels (between-group difference: $-55 \%, 95 \%$ confidence interval -27 to -73\%; $p=0.002$ ) and quality of life (between-group difference: $-11 \pm 5$ points; $p=0.04$ ). Blood pressure decreased in patients with lower sodium intake (between-group difference: $-9 \pm 5 \mathrm{mmHg} ; p=0.05$ ) without significant differences in symptomatic hypotension or other safety events ( $p>0.3$ for all).

Conclusions: Adherence assessed by 24-hour natriuresis and by the nutritionist was poor. The group allocated to sodium restriction did not show improvement in NT-proBNP. However, patients who achieved a sodium intake $<2500 \mathrm{mg} /$ day appeared to have improvements in NT-proBNP and quality of life without any adverse safety signals. ClinicalTrials.gov Identifier: NCT03351283. (Cardiol J)

Key words: heart failure, sodium intake, NT-proBNP, quality of life

\section{Introduction}

Given the primacy of sodium in the pathophysiology of heart failure (HF), it is intuitive that sodium restriction should be a primary goal of treatment [1-6]. However, despite being recommended by international guidelines, sodium restriction lacks solid clinical evidence from wellpowered randomized controlled trials $[7,8]$. In fact, most of the evidence comes either from trials assessing the effect of sodium restriction in non-HF populations such as patients with hypertension or from observational studies [9, 10]. Notably, available evidence has shown conflicting results making it difficult to support specific recommendations for sodium restriction in HF [11-19].

Traditionally, it would be expected that sodium restriction can lead to a negative sodium balance resulting in an improved volume status. However, severe sodium restriction might not be desirable because detrimental effects such as higher activation of the renin-angiotensin-aldosterone system and worse outcomes have been reported in clinical trials as well as in a large observational study $[17,19]$. Therefore, a gap in knowledge would be whether a non-severe sodium restriction could provide beneficial cardiac effects compared to a standard cardiac diet of $\sim 3 \mathrm{~g}$ of sodium/day.

Thus, in the present randomized, controlled trial the effect of sodium restriction (2 $\mathrm{g}$ of sodium/day) was tested vs. a control group (3 $g$ of sodium/day) in stable HF patients with reduced ejection fraction. Hypothesized herein, was that patients randomized to sodium restriction will show improved cardiac parameters such as B-type natriuretic peptide (BNP) levels and cardiac-related quality of life.

\section{Methods}

\section{Study design}

This was a randomized, double-blind, parallel-group trial in stable chronic HF patients with reduced ejection fraction. The study was registered in 2017 (ClinicalTrials.gov Identifier: NCT03351283).

\section{Population}

From January 2018 to November 2019, we assessed the eligibility of consecutive patients with chronic $\mathrm{HF}$ and reduced ejection fraction $(\leq 40 \%)$ who attended our tertiary care center. Inclusion criteria were: 1 ) treatment with both an angiotensin-converting-enzyme inhibitors (ACEI) or angiotensin-receptor-blockers (ARB), and a beta-blocker; 2) stable medical treatment defined as no change in medications for the prior 4 weeks; 3 ) age $\geq 18$ years; 4) systolic blood pressure equal or greater than $90 \mathrm{mmHg}$; 5 ) highly motivated patients willing to participate. Excluded patients were those with: 1) a history of a HF admission in the prior month or with a New York Heart Association class III or IV; 2) an estimated glomerular filtration rate $(\mathrm{eGFR})<30 \mathrm{~mL} / \mathrm{min} / 1.73 \mathrm{~m}^{2}$ assessed by the Chronic Kidney Disease Epidemiology Collaboration (CKD-EPI) equation; 3 ) serum sodium < $130 \mathrm{mmol} / \mathrm{L} ; 4$ ) hemoglobin $<10 \mathrm{~g} / \mathrm{dL}$; 5) patients scheduled to any intervention with the aim of improving their cardiovascular function (for example percutaneous coronary intervention, coronary artery bypass grafting, etc.); 6) valvular heart disease equal or greater than moderate degree; 7) dementia; 8 ) cancer or any other condition compromising life expectancy within the following 12 months. The study was approved by the Ethics Committee of the documented hospital and all 
participants provided written informed consent. The study was terminated when the target subject recruitment was achieved.

\section{Intervention and adherence}

Patients were randomized to either sodium restriction (goal of $2 \mathrm{~g}$ of sodium/day) vs. a control group (3 $\mathrm{g}$ of sodium/day). A 24-hour urinary collection was collected the day before randomization to estimate baseline sodium intake. During the visit for randomization, a qualified nutritionist estimated dietary sodium intake using a standardized 24-hour food diary to obtain the dietary consumption of each patient. A thorough nutritional analysis of the subjects' diets was obtained using the Food Processor $^{\circledR}$ SQL Nutrition Analysis Software (version 7.9; ESHA Research). The nutritionist then calculated and provided multiple written diets (menus) each containing either $2 \mathrm{~g}$ (sodium restriction group) or $3 \mathrm{~g}$ of sodium (control). For this study the control group would be provided with menus of $3 \mathrm{~g}$ of sodium/day as this is the upper boundary recommended by international guidelines [20]. During the initial visit, the nutritionist did a comprehensive explanation of each of the diets and educated the patients and their families with regards to hidden salt and the importance of following the provided diet. Diets were individually tailored to each patient to have appropriate macronutrients and calorie content. The nutritionist elaborated individualized menus following a comprehensive dietary approach so diets with either 2 or $3 \mathrm{~g}$ of sodium/day but had similar caloric and nutrient contents, which has been shown to be feasible [21]. Following randomization, patients were seen at 6 and 12 weeks where the nutritionist estimated dietary sodium intake with the food frequency questionnaire. Based on estimated sodium intakes, the nutritionist went over the diets with the patient to improve adherence. At the end of the intervention (week 20), another 24-hour urine collection was collected to estimate final sodium intake. The estimated sodium intakes from the 24-hour food dairy were used for advice, and the 24-hour urine collection was used to assess adherence. Completeness of 24-hour urine collections was determined on the basis of volume, with a threshold of $\geq 250 \mathrm{~mL}$ [22]. Adherence was defined as a urinary sodium excretion $<2500 \mathrm{mg}$ in the sodium restriction group, and a sodium excretion between 2500 and $3500 \mathrm{mg} /$ day in the control group.

\section{Outcomes}

The primary outcome was change in $\mathrm{N}$-terminal pro-B-type natriuretic peptide (NT-proBNP) from baseline to the end of the 20-week intervention. Secondary outcomes were 1) change in quality of life quantified by the Minnesota Living with Heart Failure Questionnaire (MLHFQ), 2) change in eGFR, and 3) survival free of the composite of mortality and hospitalization. Safety end points included hyponatremia (serum sodium $<130 \mathrm{mmol} / \mathrm{L}$ ), hyperkalemia (serum potassium $>5.5 \mathrm{mmol} / \mathrm{L}$ ), hypotension (systolic blood pressure $<90 \mathrm{mmHg}$ ) and worsening renal function (defined as an absolute increase in creatinine $\geq 0.3 \mathrm{mg} / \mathrm{dL}$ ).

\section{Sample size}

Sample size was calculated with Stata SE version 16.0. Based on the study of Paterna et al. [11] mean \pm standard deviation of BNP after 180 days of a diet with $\sim 2800 \mathrm{mg}$ of sodium/day was $555 \pm 175 \mathrm{pg} / \mathrm{mL}$ vs. $745 \pm 305 \mathrm{pg} / \mathrm{mL}$ with a diet of $\sim 1800 \mathrm{mg}$ sodium/day. For a significance level of alpha $=0.05$, and a statistical power of 0.80 , the minimum sample size was calculated as 29 patients per group. Assuming a $20 \%$ dropout rate the final sample size was estimated to be 70 patients.

\section{Randomization}

The www.randomization.com website was used to generate a simple sequential randomization plan. The nutritionist was responsible for the randomization as he was the investigator who allocated participants to the intervention and followed them during the entire study.

\section{Blinding}

Investigators involved in the assessment of outcomes as well as participants were blinded throughout the study. Participants received menus but they did not know if the menus aimed to have a sodium restriction with a goal of $2 \mathrm{~g}$ of sodium/ /day or $3 \mathrm{~g}$ of sodium/day. Baseline measurement of main variables (NT-proBNP, quality of life, eGFR, etc.) were assessed before randomization.

\section{Statistical methods}

Continuous variables were presented as mean \pm \pm standard deviation or median (quartile 1, quartile 3), according to the observed distribution. Baseline between-group differences were assessed with the Student t test or the Mann-Whitney test, as appropriate. Categorical variables were presented as absolute or relative frequencies, and between-group differences were assessed with the Pearson $\chi^{2}$ test. Changes from baseline to the end of the intervention were assessed with the paired Student $t$ test or the Wilcoxon signed-rank test. Endpoints were 
estimated as changes from baseline to the end of the intervention and were compared with the Student t test or Mann-Whitney test. Survival-free of the composite outcome was assessed with the log-rank test and the Kaplan-Meier method. Analyses were done by intention to treat with all available data. For the per protocol analysis, patients were divided into two groups based on 24-hour urinary sodium excretion at the end of the intervention: those who achieved $<$ or $\geq 2500 \mathrm{mg}$ of sodium/day. This cutoff value was chosen because this is the midpoint between 2000 and $3000 \mathrm{mg}$, which were the targets of the intervention. The goal of the per-protocol analyses was to describe if sodium restriction ( $2 \mathrm{~g}$ of sodium/day) could provide beneficial cardiac effects compared to patients who did not achieve sodium restriction. Specifically, it was not our intention to compare a specific 2 -g sodium arm vs. a specific 3 -g sodium arm but rather a sodium restriction group ( $2 \mathrm{~g})$ vs. a group that did not achieve this restriction. Sensitivity analyses were done using 2750 or 3000 $\mathrm{mg}$ of sodium/day as cutoff values, as well as with multivariable linear regression with each of the three cutoff values adjusting for age, sex, and changes in medications during the study (ACEI or ARB, and loop diuretics). For linear regression, skewed variables were log transformed to approximate normal distribution. $\mathrm{P}$ values $<0.05$ were considered statistically significant. Stata SE version 16.0 (StataCorp, College Station, TX) was used for statistical analysis.

\section{Results}

\section{Patient characteristics}

Ninety-nine patients were assessed for eligibility, seventy of whom were randomized (Suppl. Fig. 1). Seven patients in the sodium restriction group and 6 patients in the control group refused to continue participating. Therefore, $57(81 \%)$ patients completed the 20 -week intervention. Two thirds were male and ischemic heart disease was the predominant etiology. Mean sodium consumption at baseline (based on 24-hour sodium urinary excretion) was $3582 \pm 1806 \mathrm{mg} /$ day and was not significantly different between groups. Table 1 summarizes baseline characteristics of randomized patients. Except for gender and use of aldosterone antagonist, the groups were comparable.

\section{Adherence to intervention}

At baseline, estimated sodium consumption was not statistically different between groups (sodium restriction group: $3305 \pm 1989$; control group:
$3911 \pm 1533 ; \mathrm{p}=0.21$ ). Based on 24-hour recalls at 6 and 12 weeks, estimated sodium consumption was not significantly different between groups ( $p>0.10$ for both). Sodium consumption at the end of the intervention (based on 24-hour urinary collection) showed a near significant association to be lower in the sodium restriction group (sodium restriction group: $3003 \pm 1244 \mathrm{mg}$ /day; control group: $3755 \pm 1797 \mathrm{mg} /$ day; mean difference 752 , 95\% confidence interval [CI] 64 to $1568 \mathrm{mg} /$ day, $\mathrm{p}=0.07)$. However, the change in sodium intake was not significantly different between groups (sodium restriction group: $-57 \pm 1948 \mathrm{mg} /$ day; control group: $-426 \pm 1571 \mathrm{mg} /$ day; $\mathrm{p}=0.50$ ) Adherence to the intervention based on 24-hour urinary sodium was $32 \%$ and was similar between the 3 -g compared to the 2 -g group ( $28 \%$ vs. $35 \%$, respectively; $\mathrm{p}=0.55$ ).

\section{Outcomes. Intention-to-treat analysis}

In the overall population NT-proBNP did not significantly change from baseline to the end of the intervention (median change in NT-proBNP $-29 \mathrm{pg} / \mathrm{mL}$ [interquartile range -267 to $211 \mathrm{pg} /$ $\mathrm{mL}], \mathrm{p}=0.69)$. No significant changes were observed between groups $(\mathrm{p}=0.88)$ (Table 2 , Fig. 1). Quality of life quantified by the MLHFQ improved from baseline to the end of the intervention in the overall population (change $-9.3 \pm$ $\pm 19.9, \mathrm{p}<0.001)$. A near significant association was found to be an improvement in quality of life in the control group $(\mathrm{p}=0.052)$ (Table 2 , Fig. 1). No significant changes were observed for blood pressure, serum sodium, serum potassium, serum creatinine and weight between groups ( $p \geq 0.14$ for all). Fourteen patients experienced a $\mathrm{HF}$ readmission and 1 patient died. Out of the 15 events, 8 occurred in the sodium restriction group and 7 in the control group. Survival free of HF readmission or death was not significantly different between groups $(\mathrm{p}=0.89)$. The proportion of hyponatremia, hyperkalemia, hypotension, and worsening renal function was also similar between groups (Table 3 ).

\section{Per-protocol analysis}

Based on 24-hour urinary sodium excretion, $36 \%$ of patients achieved a sodium intake $<2500$ $\mathrm{mg} /$ day at the end of the intervention. In the group with $<2500 \mathrm{mg} /$ day, sodium intake statistically changed from baseline to the end of the intervention: mean change $-1076 \mathrm{mg}(95 \% \mathrm{CI}-354$ to -1798 , $\mathrm{p}=0.006$ ), while in the group with $\geq 2500 \mathrm{mg} / \mathrm{day}$, the change was not statistically significant: mean 
Table 1. Baseline characteristics of patients.

\begin{tabular}{|c|c|c|c|c|}
\hline & $\begin{array}{l}\text { Total population } \\
(\mathbf{n}=70)\end{array}$ & $\begin{array}{l}\text { Sodium restriction } \\
\qquad(\mathrm{n}=37)\end{array}$ & $\begin{array}{l}\text { Control } \\
(n=33)\end{array}$ & $\mathbf{P}$ \\
\hline \multicolumn{5}{|l|}{ Demographics } \\
\hline Age [years] & $60 \pm 12$ & $61 \pm 12$ & $58 \pm 13$ & 0.32 \\
\hline Male & $47(67 \%)$ & $20(54 \%)$ & $27(82 \%)$ & 0.014 \\
\hline \multicolumn{5}{|l|}{ Past medical history } \\
\hline Diabetes & $26(37 \%)$ & $14(38 \%)$ & $12(36 \%)$ & 0.90 \\
\hline Hypertension & $34(49 \%)$ & $19(51 \%)$ & $15(45 \%)$ & 0.62 \\
\hline Dyslipidemia & $36(51 \%)$ & $17(46 \%)$ & $19(58 \%)$ & 0.33 \\
\hline Ischemic heart disease & $51(73 \%)$ & $23(62 \%)$ & $28(85 \%)$ & 0.058 \\
\hline LVEF $[\%]$ & $30 \pm 7$ & $29 \pm 8$ & $32 \pm 7$ & 0.11 \\
\hline \multicolumn{5}{|l|}{ Physical exam and functional class } \\
\hline Systolic blood pressure [mmHg] & $111 \pm 15$ & $110 \pm 16$ & $112 \pm 15$ & 0.64 \\
\hline Body mass index $\left[\mathrm{kg} / \mathrm{m}^{2}\right]$ & $28.1 \pm 4.7$ & $27.3 \pm 4.6$ & $29.0 \pm 4.8$ & 0.12 \\
\hline NYHA class I & $31(44 \%)$ & $16(43 \%)$ & $15(45 \%)$ & 0.85 \\
\hline NYHA class II & $39(56 \%)$ & $21(57 \%)$ & $18(55 \%)$ & 0.85 \\
\hline MLHFQ (points) & $38(19,58)$ & $35(12,54)$ & $40(27,59)$ & 0.15 \\
\hline \multicolumn{5}{|l|}{ Laboratory data } \\
\hline Serum sodium [mmol/L] & $141 \pm 4$ & $141 \pm 3$ & $142 \pm 4$ & 0.51 \\
\hline eGFR $\left[\mathrm{mL} / \mathrm{min} / 1.73 \mathrm{~m}^{2}\right]$ & $64 \pm 25$ & $67 \pm 25$ & $62 \pm 24$ & 0.37 \\
\hline NT-proBNP [pg/mL] & $762(363,2683)$ & $1402(378,3387)$ & $540(350,1704)$ & 0.14 \\
\hline Urinary sodium excretion [mg/day] & $3268(2225,4537)$ & $3259(1645,4209)$ & $3419(2990,4605)$ & 0.12 \\
\hline \multicolumn{5}{|l|}{ Medication } \\
\hline $\begin{array}{l}\text { Loop diuretic dose (mg of furosemide } \\
\text { equivalent/day) }\end{array}$ & $20(0,40)$ & $40(0,40)$ & $20(0,40)$ & 0.64 \\
\hline Loop diuretics & $50(70 \%)$ & $27(73 \%)$ & $23(70 \%)$ & 0.76 \\
\hline ACEI, ARB or ARNI & $66(94 \%)$ & $35(95 \%)$ & $31(94 \%)$ & $>0.99$ \\
\hline Beta-blocker & $63(90 \%)$ & $34(92 \%)$ & $29(88 \%)$ & 0.70 \\
\hline Aldosterone antagonist & $51(73 \%)$ & $31(84 \%)$ & $20(61 \%)$ & 0.029 \\
\hline
\end{tabular}

Continuous data is shown as mean \pm standard deviation, or median (quartile 1, quartile 3). ACEI - angiotensin converting enzyme inhibitor; ARB - angiotensin receptor blocker; ARNI — angiotensin receptor neprilysin inhibitor; eGFR — estimated glomerular filtration rate; LVEF left ventricular ejection fraction; MLHFQ - Minnesota Living with Heart Failure Questionnaire; NT-proBNP - N-terminal pro-B-type natriuretic peptide; NYHA - New York Heart Association

change $+263(95 \% \mathrm{CI}-437$ to $+963, \mathrm{p}=0.45)$. The between groups difference was statistically different: $1339 \mathrm{mg}$ (95\% CI 2398 to $280 \mathrm{mg} /$ day); $\mathrm{p}=0.01$ (Fig. 2). NT-proBNP levels $(\mathrm{p}=0.01$ ) and quality of life $(\mathrm{p}=0.04)$ improved in the group with $<2500 \mathrm{mg} /$ day compared to the group with $\geq 2500 \mathrm{mg} /$ day (Fig. 2, Table 4). Likewise, blood pressure decreased in the patients with lower sodium consumption compared to the other group $(p=0.05)$. No significant changes were observed for serum sodium, potassium, creatinine and weight between groups ( $\mathrm{p}>0.10$ for all) (Fig. 2, Table 4). The proportion of hyponatremia, hyperkalemia, hypotension, and worsening renal function was similar between groups (Table 3 ). In sensitivity analysis, similar results were observed for NT-proBNP levels and quality of life in favor of the group with lower sodium intake when using cutoff values of 2750 or $3000 \mathrm{mg}$, and after adjusting for covariables with the three different cutoff values (Suppl. Table 1).

\section{Discussion}

There are scarce data from randomized trials to support an appropriate level of sodium restriction in patients with HF. The current main findings are: 1) A nutritional intervention aimed to reduce sodium intake did not reduce NT-proBNP levels; however, 2) Patients who achieved $<2500 \mathrm{mg}$ of 


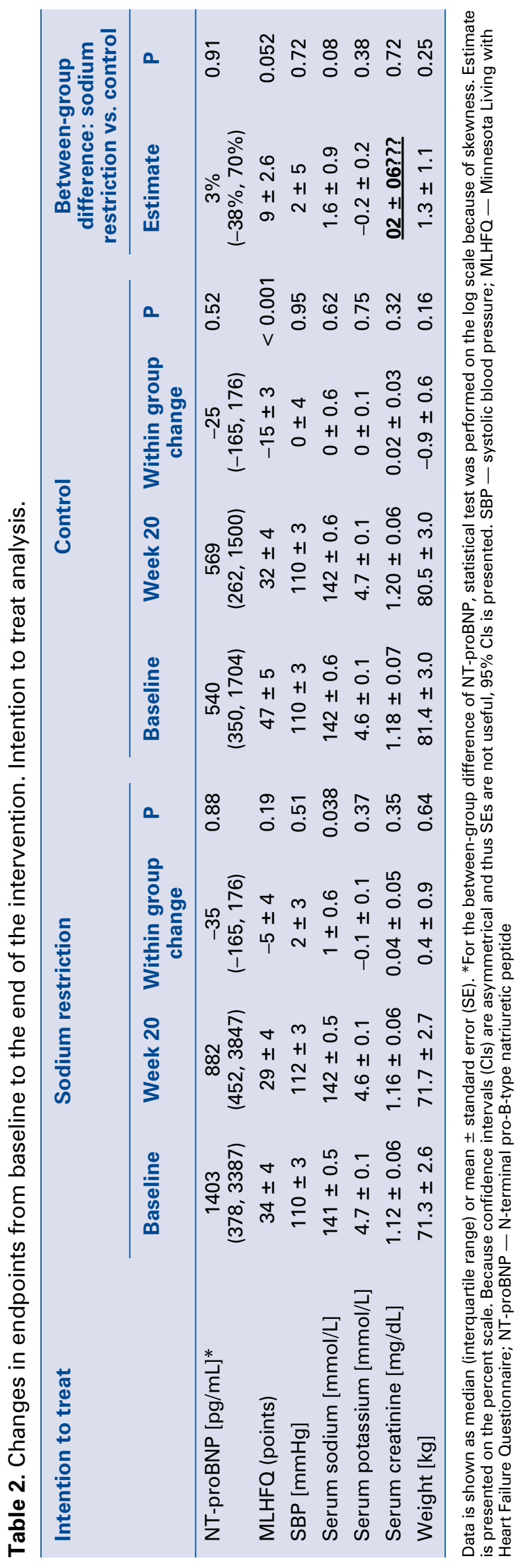

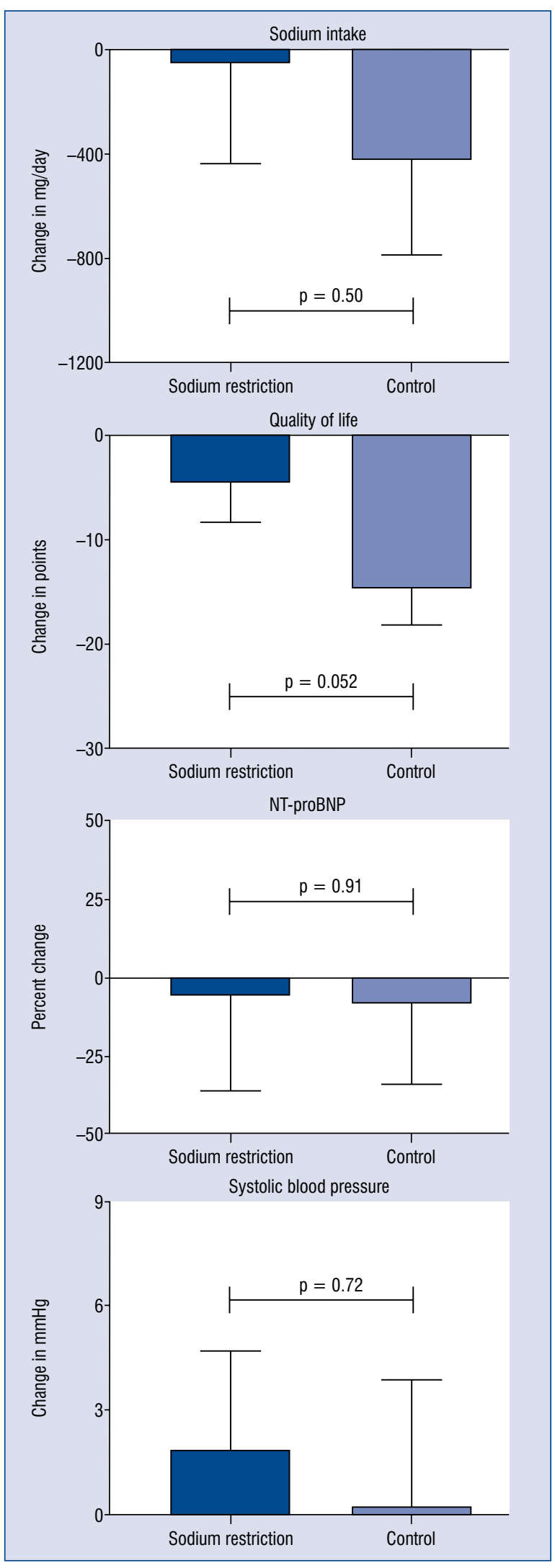

Figure 1. Intention to treat analysis. Bars show the mean change in parameter. Error bars show standard error of the mean; NT-proBNP - N-terminal pro-B-type natriuretic peptide. 
Table 3. Safety parameters.

\begin{tabular}{|c|c|c|c|c|c|c|}
\hline & \multicolumn{3}{|c|}{ Intention to treat } & \multicolumn{3}{|c|}{ Per protocol } \\
\hline & $\begin{array}{l}\text { Sodium } \\
\text { restriction } \\
\text { (n) }\end{array}$ & $\begin{array}{c}\text { Control } \\
\text { (n) }\end{array}$ & $\mathbf{P}$ & $\begin{array}{c}<2500 \mathrm{mg} \\
\text { sodium/ } \\
\text { /day }(\mathrm{n})\end{array}$ & $\begin{array}{c}\geq 2500 \text { mg } \\
\text { sodium/ } \\
\text { /day (n) }\end{array}$ & $\mathbf{P}$ \\
\hline Serum sodium $<130 \mathrm{mmol} / \mathrm{L}$ & 0 & 0 & - & 0 & 0 & - \\
\hline Serum potassium $>5.5 \mathrm{mmol} / \mathrm{L}$ & 1 & 0 & $>0.99$ & 1 & 0 & 0.35 \\
\hline Systolic blood pressure $<90 \mathrm{mmHg}$ & 2 & 2 & $>0.99$ & 1 & 2 & $>0.99$ \\
\hline Worsening renal function ( $>0.3 \mathrm{mg} / \mathrm{dL}$ ) & 3 & 1 & 0.62 & 2 & 2 & 0.61 \\
\hline
\end{tabular}

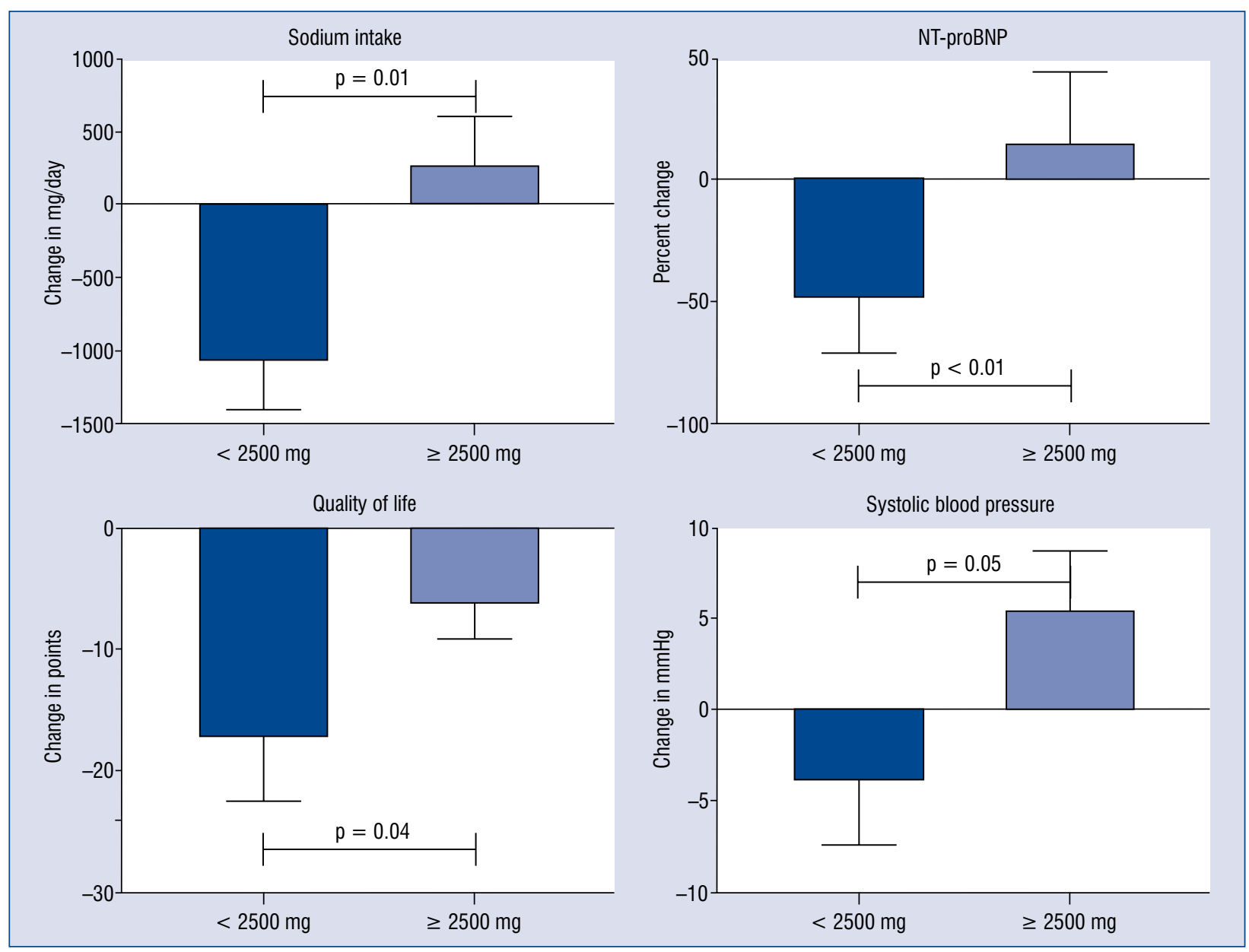

Figure 2. Per protocol analysis. Bars show mean change in parameter. Error bars show standard error of the mean; NT-proBNP — N-terminal pro-B-type natriuretic peptide.

sodium/day showed improvements in NT-proBNP levels and quality of life; 3) Sodium intake within the limits of the present study appeared to be safe as very few safety issues were noted; 4) Even in highly motivated patients with a tight follow-up, adherence to sodium restriction was remarkably low.
In the Geriatric Out-of-Hospital Randomized Meal Trial in Heart Failure (GOURMET) and Prevent Adverse Outcomes in Heart Failure by Limiting Sodium Pilot Study (PROHIBIT), 4 weeks and 12 weeks of interventions aimed at reducing sodium intake, respectively, were not 


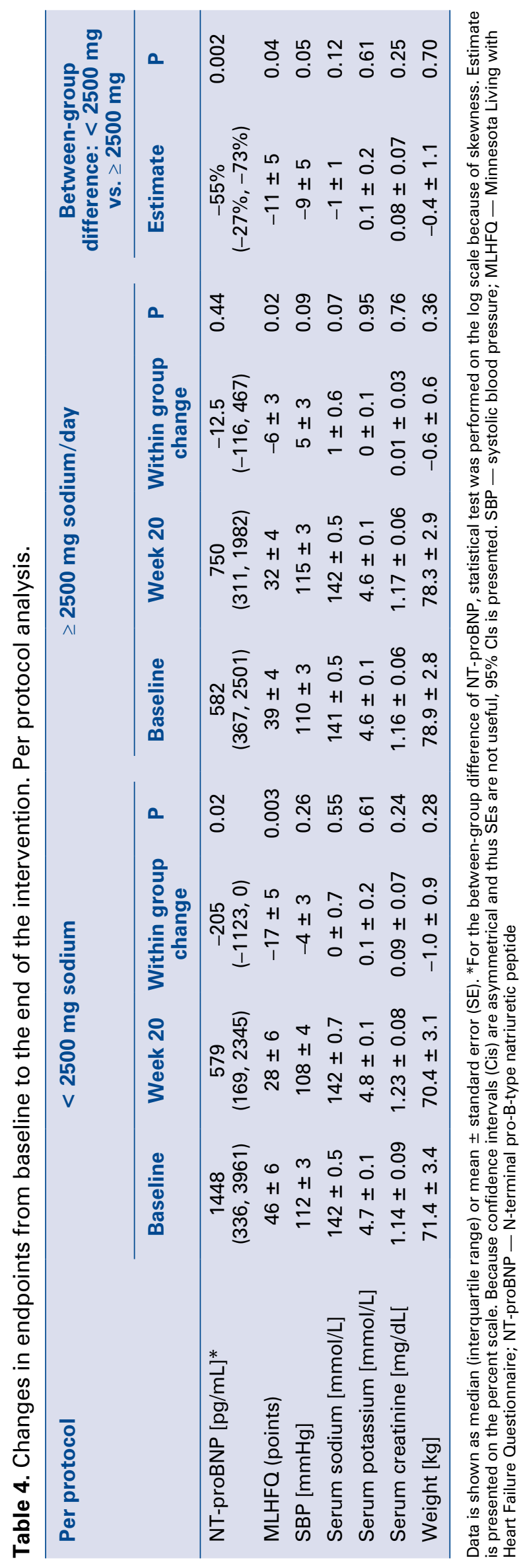

associated with reductions in BNPs [23, 24]. Conversely, in the Study of Dietary Intervention Under 100 MMOL in Heart Failure (SODIUM-HF), sodium restriction for 6 months did result in a significant reduction of BNP levels [25]. In the present study, a 20 -week intervention did not show improvements in NT-proBNP levels, likely due to poor adherence. However, patients who achieved a sodium intake $<2500 \mathrm{mg} /$ day did show improvement in NT-proBNP levels. Importantly, length of interventions was notably different among the 4 mentioned studies. Shorter interventions ( 2 weeks in GOURMET and 12 weeks in PROHIBIT) were not associated with improvements in NT-proBNP levels. Conversely, longer interventions (6 months in the SODIUM-HF and 20 weeks in the perprotocol analysis of the present study) did show a potential benefit. Therefore, one might hypothesize that the effect of sodium restriction on natriuretic peptides may be possible in the long-term.

Regarding quality of life, a statistically significant improvement was observed in the group that achieved $<2500 \mathrm{mg}$ of sodium/day compared to that of the control group. This finding is consistent with the GOURMET, PROHIBIT, and SODIUM-HF studies, in which interventions aimed to reduce sodium intake showed improvement in quality of life despite somehow different interventions: food was provided in the first two, and written menus in the last one [23-25]. Therefore, it is likely that sodium restriction could have improved quality of life, and these beneficial effects may appear as soon as 4 weeks in the GOURMET study and may continue for up to 6 months (SODIUM-HF and the present study).

Importantly, neither in the present study nor in the other 3 randomized trials an increased risk of adverse outcomes was observed in patients allocated to sodium restriction [23-25]. These findings contrast with the study performed by Italian investigators where patients with intensive restriction compared to moderate sodium restriction $(1800 \mathrm{mg}$ vs. $2800 \mathrm{mg}$ of sodium/day, respectively) showed higher risk of hospital readmission [11]. Notably, in that study patients were treated with higher doses of loop diuretics (250 $\mathrm{mg}$ to $500 \mathrm{mg}$ of furosemide per day) compared to the present study ( $\sim 20 \mathrm{mg}$ of furosemide per day) or the PROHIBIT trial ( $\sim 50 \mathrm{mg}$ of furosemide equivalents per day). Given that loop diuretics strongly enhance neurohormonal activation [26, 27], and lower sodium chloride intake also stimulates the renin-angiotensin-aldosterone system [28, 29], it is possible that these differences drove the outcomes in that study. Another 
remarkable difference is that in the present study, the GOURMET, and PROHIBIT trials most patients were taking ACEI/ARBs, while in the Italian study only $30 \%$ were taking captopril. The effect of sodium restriction in patients with or without ACEI/ARB was reported in the HART study (A Self-management Intervention for Mild to Moderate Heart Failure) where worse outcomes with sodium restriction were observed only in patients who were not receiving ACEI/ARB [19].

Another remarkable observation in the present study is that it is very hard for patients with HF to adhere to diet interventions that aim to decrease sodium intake. This finding is consistent with a previous trial where very few patients achieved a sodium consumption $<2000 \mathrm{mg}$ /day even with dietitian education, or even in the PROHIBIT study where adherence was $\sim 50 \%$ despite having food provided [24, 30]. The SODIUM-HF trial will provide unique information to understand if diet interventions aiming to decrease sodium intake can improve clinical outcomes [31].

With regards to medication, it was noted that $70 \%$ of the population were receiving loop diuretics which has been shown to potentially affect the accuracy of 24-hour urine collections likely because in stable HF patients loop diuretics are key to maintaining sodium homeostasis as demonstrated in a recent study where loop diuretic omission resulted in a $50 \%$ reduction in natriuresis $[32,33]$. Importantly, in the present study the use of aldosterone antagonists was higher in the sodium restriction group at baseline, and although all patients were taking $\leq 25 \mathrm{mg}$ of spironolactone, which is not typically considered a natriuretic dose, some potential natriuretic or cardiac effect of these drugs cannot be negated and thus a possible influence on the observed results. Interestingly, serum sodium actually increased in the sodium restriction group; however, the magnitude of the change was not clinically relevant $(1 \mathrm{mmol} / \mathrm{L}$ during the 20 -week intervention) and the between-group difference did not reach statistical significance $(\mathrm{p}=0.08)$.

\section{Limitations of the study}

This was a single-center study with a relatively small sample size; thus, results should be interpreted cautiously. Namely, the present study might be underpowered to detect a smaller difference of change in NT-proBNP levels. Baseline sodium intake was not excessively high; therefore, results may not be extrapolated to patients with higher sodium intake. Assessments of sodium intake 4 times during a 20 -week period and do not con- sider whether there were large fluctuations between these times. Adherence was assessed by 24 -hour urinary collections, which may not be a reproducible method, and completeness of urine collections was determined on volume alone, which may be an insensitive method [34]. In addition, adherence to the intervention was poor. Food was not provided but patients were asked to follow written diets, which decreases adherence to the intervention. However, in the rigorously conducted PROHIBIT study diet compliance was $\sim 50 \%$ in support of the notion that diet interventions are extremely challenging [24]. NT-proBNP showed a near statistical association to be lower in the control group at baseline, and thus some impact cannot be ruled out on the results because the primary outcome was a change in NT-proBNP. Finally, there were more men in the control group which could have potentially affected adherence to the intervention and consequently the observed results.

\section{Conclusions}

Adherence to an intervention aimed to reduce sodium intake was poorly assessed both with the 24-hour urinary sodium excretion and by the nutritionist; thus, this study shows the challenges of this type of intervention and suggests its limited usefulness in future studies. No significant improvement in NT-proBNP levels were observed in patients allocated to an intervention aiming to reduce sodium intake. However, patients who achieved a sodium intake $<2500 \mathrm{mg} /$ day at the end of the 20 -week intervention did show improvements in NT-proBNP levels and quality of life without any adverse safety signal.

\section{Acknowledgments}

We thank "Comision Nacional de Ciencia y Tecnologia" (CONACYT) for the support provided in the development of this protocol (Dr. Juan B. Ivey-Miranda CVU 427063). Dr. Juan B. Ivey-Miranda belongs to the "Programa de Maestria y Doctorado en Ciencias Médicas, Odontologicas y de la Salud" from the "Universidad Nacional Autonoma de Mexico”.

\section{Funding}

This study was supported by Fondo de Investigación en Salud, Instituto Mexicano del Seguro Social, grant FIS/IMSS/PROT/G17-2/1721.

Conflict of interest: None declared 


\section{References}

1. Cadnapaphornchai MA, Gurevich AK, Weinberger HD, et al. Pathophysiology of sodium and water retention in heart failure. Cardiology. 2001; 96(3-4): 122-131, doi: 10.1159/000047396, indexed in Pubmed: 11805379.

2. Damman K, Ter Maaten JM, Coster JE, et al. Clinical importance of urinary sodium excretion in acute heart failure. Eur J Heart Fail. 2020; 22(8): 1438-1447, doi: 10.1002/ejhf.1753, indexed in Pubmed: 32086996.

3. Gheorghiade M, Filippatos G, De Luca L, et al. Congestion in acute heart failure syndromes: an essential target of evaluation and treatment. Am J Med. 2006; 119(12 Suppl 1): S3-SS10, doi: 10.1016/j.amjmed.2006.09.011, indexed in Pubmed: 17113398.

4. Mullens W, Verbrugge FH, Nijst P, et al. Renal sodium avidity in heart failure: from pathophysiology to treatment strategies. Eur Heart J. 2017; 38(24): 1872-1882, doi: 10.1093/eurheartj/ehx035, indexed in Pubmed: 28329085.

5. Ponikowski P, Voors AA, Anker SD, et al. 2016 ESC Guidelines for the diagnosis and treatment of acute and chronic heart failure: The Task Force for the diagnosis and treatment of acute and chronic heart failure of the European Society of Cardiology (ESC). Developed with the special contribution of the Heart Failure Association (HFA) of the ESC. Eur J Heart Fail. 2016; 18(8): 891-975, doi: 10.1002/ejhf.592, indexed in Pubmed: 27207191.

6. Yancy CW, Jessup M, Bozkurt B, et al. 2013 ACCF/AHA guideline for the management of heart failure: a report of the American College of Cardiology Foundation/American Heart Association Task Force on Practice Guidelines. J Am Coll Cardiol. 2013; 62(16): e147-239, doi: 10.1016/j.jacc.2013.05.019, indexed in Pubmed: 23747642.

7. Butler J, Papadimitriou L, Georgiopoulou V, et al. Comparing Sodium Intake Strategies in Heart Failure: Rationale and Design of the Prevent Adverse Outcomes in Heart Failure by Limiting Sodium (PROHIBIT) Study. Circ Heart Fail. 2015; 8(3): 636-645, doi: $10.1161 /$ CIRCHEARTFAILURE.114.001700, indexed in Pubmed: 25991806.

8. Gupta D, Georgiopoulou VV, Kalogeropoulos AP, et al. Dietary sodium intake in heart failure. Circulation. 2012; 126(4): 479-485, doi: 10.1161/CIRCULATIONAHA.111.062430, indexed in Pubmed: 22825409.

9. WHO Guidelines Approved by the Guidelines Review Committee. Guideline: Sodium Intake for Adults and Children. Geneva: World Health Organization. 2012.

10. Graudal NA, Hubeck-Graudal T, Jurgens G. Effects of low sodium diet versus high sodium diet on blood pressure, renin, aldosterone, catecholamines, cholesterol, and triglyceride. Cochrane Database Syst Rev. 2011(11): CD004022, doi: 10.1002/14651858. CD004022.pub3, indexed in Pubmed: 22071811.

11. Paterna S, Parrinello G, Cannizzaro S, et al. Medium term effects of different dosage of diuretic, sodium, and fluid administration on neurohormonal and clinical outcome in patients with recently compensated heart failure. Am J Cardiol. 2009; 103(1): 93-102, doi: 10.1016/j.amjcard.2008.08.043, indexed in Pubmed: 19101237.

12. Aronow WS, Shamliyan TA. Dietary sodium interventions to prevent hospitalization and readmission in adults with congestive heart failure. Am J Med. 2018; 131(4): 365-370.e1, doi: 10.1016/j. amjmed.2017.12.014, indexed in Pubmed: 29307539.

13. Paterna S, Gaspare P, Fasullo S, et al. Normal-sodium diet compared with low-sodium diet in compensated congestive heart failure: is sodium an old enemy or a new friend? Clin Sci (Lond).
2008; 114(3): 221-230, doi: 10.1042/CS20070193, indexed in Pubmed: 17688420.

14. Song EK, Moser DK, Dunbar SB, et al. Dietary sodium restriction below $2 \mathrm{~g}$ per day predicted shorter event-free survival in patients with mild heart failure. Eur J Cardiovasc Nurs. 2014; 13(6): 541-548, doi: $10.1177 / 1474515113517574$, indexed in Pubmed: 24366983.

15. Paterna S, Di Pasquale P, Parrinello G, et al. Changes in brain natriuretic peptide levels and bioelectrical impedance measurements after treatment with high-dose furosemide and hypertonic saline solution versus high-dose furosemide alone in refractory congestive heart failure: a double-blind study. J Am Coll Cardiol. 2005; 45(12): 1997-2003, doi: 10.1016/j.jacc.2005.01.059, indexed in Pubmed: 15963399.

16. Lennie TA, Song EK, Wu JR, et al. Three gram sodium intake is associated with longer event-free survival only in patients with advanced heart failure. J Card Fail. 2011; 17(4): 325-330, doi: 10.1016/j.cardfail.2010.11.008, indexed in Pubmed: 21440871.

17. Parrinello G, Di Pasquale P, Licata G, et al. Long-term effects of dietary sodium intake on cytokines and neurohormonal activation in patients with recently compensated congestive heart failure. J Card Fail. 2009; 15(10): 864-873, doi: 10.1016/j.cardfail.2009.06.002, indexed in Pubmed: 19944363.

18. Son YJ, Lee Y, Song EK. Adherence to a sodium-restricted diet is associated with lower symptom burden and longer cardiac eventfree survival in patients with heart failure. J Clin Nurs. 2011; 20(21-22): 3029-3038, doi: 10.1111/j.1365-2702.2011.03755.x, indexed in Pubmed: 21707808.

19. Doukky R, Avery E, Mangla A, et al. Impact of dietary sodium restriction on heart failure outcomes. JACC Heart Fail. 2016; 4(1): 24-35, doi: 10.1016/j.jchf.2015.08.007, indexed in Pubmed: 26738949 .

20. Lindenfeld J, Albert NM, Boehmer JP, et al. Heart Failure Society of America. HFSA 2010 Comprehensive Heart Failure Practice Guideline. J Card Fail. 2010; 16(6): e1-e194, doi: 10.1016/j.cardfail.2010.04.004, indexed in Pubmed: 20610207.

21. Colin-Ramirez E, McAlister FA, Zheng Y, et al. Changes in dietary intake and nutritional status associated with a significant reduction in sodium intake in patients with heart failure. A sub-analysis of the SODIUM-HF pilot study. Clin Nutr ESPEN. 2016; 11: e26-e32, doi: 10.1016/j.clnesp.2015.11.002, indexed in Pubmed: 28531423.

22. Stamler J, Elliott P, Dennis B, et al. INTERMAP Research Group. INTERMAP: background, aims, design, methods, and descriptive statistics (nondietary). J Hum Hypertens. 2003; 17(9): 591-608, doi: 10.1038/sj.jhh.1001603, indexed in Pubmed: 13679950.

23. Hummel SL, Karmally W, Gillespie BW, et al. Home-Delivered meals postdischarge from heart failure hospitalization. Circ Heart Fail. 2018; 11(8): e004886, doi: 10.1161/CIRCHEARTFAILURE.117.004886, indexed in Pubmed: 30354562.

24. Kalogeropoulos A, Papadimitriou L, Georgiopoulou VV, et al. Low- Versus Moderate-Sodium Diet in Patients With Recent Hospitalization for Heart Failure: The PROHIBIT (Prevent Adverse Outcomes in Heart Failure by Limiting Sodium) Pilot Study. Circ Heart Fail. 2020; 13(1): e006389, doi: 10.1161/CIRCHEARTFAILURE.119.006389, indexed in Pubmed: 31959014.

25. Colin-Ramirez E, McAlister FA, Zheng Y, et al. The long-term effects of dietary sodium restriction on clinical outcomes in patients with heart failure. The SODIUM-HF (Study of Dietary Intervention Under $100 \mathrm{mmol}$ in Heart Failure): a pilot study. Am Heart J. 2015; 169(2): 274-281.e1, doi: 10.1016/j.ahj.2014.11.013, indexed in Pubmed: 25641537. 
26. Chen HH, Redfield MM, Nordstrom LJ, et al. Angiotensin II AT1 receptor antagonism prevents detrimental renal actions of acute diuretic therapy in human heart failure. Am J Physiol Renal Physiol. 2003; 284(5): F1115-F1119, doi: 10.1152/ajprenal.00337.2002, indexed in Pubmed: 12676739.

27. Francis GS, Siegel RM, Goldsmith SR, et al. Acute vasoconstrictor response to intravenous furosemide in patients with chronic congestive heart failure. Activation of the neurohumoral axis. Ann Intern Med. 1985; 103(1): 1-6, doi: 10.7326/0003-4819-1031-1, indexed in Pubmed: 2860833.

28. Cholewa BC, Mattson DL. Role of the renin-angiotensin system during alterations of sodium intake in conscious mice. Am J Physiol Regul Integr Comp Physiol. 2001; 281(3): R987-R993, doi: 10.1152/ajpregu.2001.281.3.R987, indexed in Pubmed: 11507017 .

29. Guython AC, Hall JE. Textbook of medical physiology. Saunders, Philadelphia, PA 2000.

30. Arcand JA, Brazel S, Joliffe C, et al. Education by a dietitian in patients with heart failure results in improved adherence with a sodium-restricted diet: a randomized trial. Am Heart J. 2005;
150(4): 716, doi: 10.1016/j.ahj.2005.02.016, indexed in Pubmed: 16209971.

31. Colin-Ramirez E, Ezekowitz JA. SODIUM-HF investigators. Rationale and design of the Study of Dietary Intervention Under 100 MMOL in Heart Failure (SODIUM-HF). Am Heart J. 2018; 205: 8796, doi: 10.1016/j.ahj.2018.08.005, indexed in Pubmed: 30205241.

32. Arcand J, Floras JS, Azevedo E, et al. Evaluation of 2 methods for sodium intake assessment in cardiac patients with and without heart failure: the confounding effect of loop diuretics. Am J Clin Nutr. 2011; 93(3): 535-541, doi: 10.3945/ajcn.110.004457, indexed in Pubmed: 21191141.

33. Dauw J, Martens P, Tersalvi G, et al. Diuretic response and effects of diuretic omission in ambulatory heart failure patients on chronic low-dose loop diuretic therapy. Eur J Heart Fail. 2021; 23(7): 1110-1119, doi: 10.1002/ejhf.2145, indexed in Pubmed: 33641220.

34. John KA, Cogswell ME, Campbell NR, et al. Accuracy and Usefulness of Select Methods for Assessing Complete Collection of 24-Hour Urine: A Systematic Review. J Clin Hypertens (Greenwich). 2016; 18(5): 456-467, doi: 10.1111/jch.12763, indexed in Pubmed: 26726000. 